WTEREFACETEENOLÓGCACA

\title{
A EVOLUÇÃO DO MERCADO DO FRANGO CAIPIRA NO BRASIL
}

\author{
THE EVOLUTION OF THE CHICKEN MARKET IN BRAZIL
}

\author{
Larissa Izac dos Santos - larissaizac10@gmail.com \\ Faculdade de Tecnologia (Fatec) - Taquaritinga - SP - Brasil \\ Alexandro Oliveira dos Santos - alexoliveira1998@outlook.com \\ Faculdade de Tecnologia (Fatec) - Taquaritinga - SP - Brasil \\ Edmilson Eduardo Augusto - eaugusto@aedu.com \\ Faculdade de Tecnologia (Fatec) - Taquaritinga - SP - Brasil \\ Mateus Rafael dos Santos Gazoli - matt.gazoli@gmail.com \\ Faculdade de Tecnologia (Fatec) - Taquaritinga - SP - Brasil \\ Marcos Alberto Claudio Pandolfi - marcos.pandolfi@fatectq.edu.br \\ Faculdade de Tecnologia (Fatec) - Taquaritinga - SP - Brasil
}

DOI: 10.31510/infa.v17i2.943

Data de publicação: 18/12/2020

\section{RESUMO}

Com o crescimento considerável do agronegócio nos últimos tempos e tendo um elevado impacto econômico em todo o mundo, o agronegócio tem vindo a acrescentar muito no meio da agricultura, da avicultura e do agronegócio. Hoje, o Brasil é um dos maiores celeiros produtores mundiais de alimentos, produzindo 10,5 milhões de toneladas de carne bovina e 4,2 milhões de toneladas de carne suína. Atualmente, a produção avícola tem vindo a aumentar, produzindo 13,15 milhões de toneladas em 2019. O Brasil é um país muito desenvolvido em relação à carne de frango, ficando atrás apenas dos Estados Unidos e da China no ranking da produção. A comercialização de galinha começou após a Segunda Guerra Mundial, devido à escassez de alimentos, sendo feita para o seu próprio sustento e rendimento familiar. O presente trabalho visa descrever o agronegócio, enfatizando o consumo de carne de frango e a evolução do mercado de frango caipira. Hoje os consumidores estão a tornar-se muito conscientes e à procura de alimentos muito mais saudáveis, por isso a comercialização da carne "caipira" está a crescer gradualmente, porque a carne não tem aditivos químicos com menor teor calórico e elevado teor proteico, acrescentando assim muitos benefícios para o consumidor. Mesmo sendo um mercado emergente, ele tem mantido um crescimento considerável, principalmente na produção familiar, e tendo um grande potencial de desenvolvimento no mercado interno.

Palavras-chave: Agronegócio. Avicultura. Frango Caipira. 


\begin{abstract}
With the considerable growth of agribusiness in recent times and having a high economic impact all over the world, agribusiness has been adding a lot in the midst of agriculture, poultry and agribusiness. Today, Brazil is one of the world's largest food-producing granaries, producing 10.5 million tons of beef and 4.2 million tons of pork. Currently, poultry production has been increasing, producing 13.15 million tons in 2019. Brazil is a very developed country in relation to chicken meat, second only to the United States and China in the production ranking. The commercialization of chicken started after World War II, due to food shortages, being made for their own sustenance and family income. The present work aims to describe the agribusiness, emphasizing the consumption of chicken meat and the evolution of the market for rustic chicken. Today the consumers are becoming very aware and looking for much healthier food, because of this the commercialization of "caipira" meat is gradually growing, because the meat does not have chemical additives have a lower calorie content and high protein content, thus adding many benefits for the consumer. Even being an emerging market, it has maintained a considerable growth, mainly in family production, and has a great development potential in the domestic market.
\end{abstract}

Keywords: Agribusiness. Poultry farming. Ruistic Chicken.

\title{
1 INTRODUÇÃO
}

O agronegócio é considerado o setor mais influente na economia nacional, que responde por aproximadamente um terço do PIB do Brasil (PACHECO, 2012). Abbade (2014) disse que a agricultura é uma atividade de alto embate econômico, e os países em desenvolvimento podem usar sua competência agrícola e métodos naturais para analisar seu próprio caminho, a fim de buscar o avanço econômico e o progresso sustentável. Hoje o Brasil tem uma visibilidade muito ampla nesse ramo, pois ele é um dos maiores "celeiros" do mundo (THE ECONOMIST, 2010), havendo uma alta produtividade alimentícia mundialmente (CONTINI; MARTHA, 2010).

O agronegócio brasileiro inclui funções econômicas basicamente relacionadas a insumos agrícolas, como fertilizantes, pesticidas, produtos corretivos, produção agrícola incluindo lavouras, pecuária, florestas e indústrias extrativas, industrialização agrícola seguido de produtos primários, entre outros (MAPA, 2011). O Departamento de Agricultura dos Estados Unidos (USDA) compara a produção de carnes nos últimos anos e estima que no ano de 2020 o Brasil deverá produzir 10,5 milhões de toneladas de carne bovina e 4,2 milhões de toneladas de carne suína (COMUNIDADE, 2020). Em 2019, a produção de frango atingiu 13,15 milhões de toneladas, um aumento de $2,3 \%$ em relação ao ano anterior. 


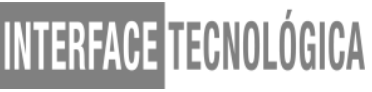

(AGENCIABRASIL,2019) Já a previsão para 2022 indica que o consumo de carne de frango aumentará cerca de 1,5\% (AVISITE, 2013).

O Brasil pode ser considerado um país desenvolvido quando o assunto é voltado para a produção de carne de frango, sendo ele referência no setor colocando-se, como segundo maior produtor mundial conforme (CONAB, 2017). Segundo dados da Associação Brasileira de Proteína Animal (2019), em relação exportação de frango em 2018, o Brasil foi considera o maior exportador, embora sua produção tenha caído cerca de $1,5 \%$ em relação ao ano passado (ABPA, 2019).

A cadeia produtiva da carne de frango abrange diversos setores, desde produtores, fabricantes, transportadores, abatedouro, equipamentos, distribuição e consumidores finais (EMBRAPA, 2020).

A industrialização e comercialização do frango de corte se iniciaram por conta da escassez de alimentos após a Segunda Guerra Mundial, onde passou a ser feito criações de galinhas para o próprio sustento e venda, assim contribuindo para a renda familiar na época e até os dias atuais. (GHERARDI, 2013).

Segundo Silva (2007) diz que juntamente com o desenvolvimento e aprimoramento genético, também com a inclusão de novas tecnologias, e novas instalações mais adequadas, aos alimentos e a colaboração entre produtores e agroindústrias estabelecidas por meio de contratos integrados, seu processo produtivo tornou-se assim mais intensivo a partir do ano de 1960.

Diferente da produção industrial, de acordoo Souza (2009) existe uma concepção que as aves caipiras tendem a possuir alta simplicidade e resistência em relação aos frangos de escala industrial, os frangos caipiras podem ter uma maior facilidade de adequações em relação ao sistema de regime e criação alimentício.

O presente trabalho tem como objetivo descrever o agronegócio no Brasil, falando sobre o consumo da carne de frango e dando ênfase na evolução do mercado e o crescimento da carne de frango caipira no Brasil.

\section{FUNDAMENTAÇÃO TEÓRICA}

Segundo Souza Junior (2020) A avicultura alternativa nos últimos tempos, vem se destacando e se desenvolvendo gradativamente, não apenas no âmbito econômico, agregando 
valor ao produto, mas também vem se aprimorando em todos os aspectos do bem-estar animal, principalmente no setor de criação. Assim gerando um alto custo na oferta e demanda do frango/galinha caipira (MORAIS et al., 2015).

Os frangos caipiras usados na criação alternativa e produções naturais, passam por menos estresse em comparação a produção intensiva e industrial, onde as carnes das aves submetidas a criação natural são muito mais saborosas e com um teor de colesterol muito baixo (BARBOSA, 2007).

O frango é considerado uma das carnes com maior teor de proteínas e alto teor de aminoácidos, deste modo sendo uma carne de muitos benefícios agregados. (VENTURINI; SARCINELLI; SILVA, 2007). Freitas (2020) diz que devido o preço ser relativamente barato, ter uma alta qualidade nutricional e ser de fácil preparo, a carne de frango é uma das principais escolhas para o consumidor brasileiro. Carrijo (2005) salienta que com o desenvolvimento tecnológico que abrange a agroindústria e a avicultura brasileira, se possibilita o ganho nos produtos de baixo custo, com isso obtendo uma alta qualidade e conseguindo atingir a competitividade de alta escala no mercado mundial.

No entanto, com o crescimento da competitividade no mercado e a evolução da consciência do consumidor, a avicultura passou por algumas alterações na cadeia produtiva proporcionar produtos diferenciados e de maior valor agregado, como a produção alternativa de frangos caipiras (SOUZA, 2004).

\begin{abstract}
A exploração de aves caipira é uma das atividades agropecuárias com perfil mais apropriado para os agricultores familiares. Além de enraizada na tradição cultural dos produtores da região, requer baixos investimentos, proporciona boa lucratividade, é ecologicamente correta e tem uma importância fundamental para a segurança alimentar das famílias rurais do semiárido (OLIVEIRA, et al. 2008, p. 10).
\end{abstract}

Segundo o Globo Rural (2016) o Brasil se consolidou como um dos maiores produtores de carne de frango do mundo. Isso ocorreu porque internamente o comércio foi mantido aquecido e com demanda adequada, também contribuiu para esse cenário o aumento das exportações, que chegaram a quatro milhões de toneladas. Com isso a estimativa de crescimento de carne de frango para os próximos dez anos são muito grandes, tendo uma porcentagem de 33,4\%, havendo uma produção de 13,440 milhões toneladas no ano de 2017 e 17,930 milhões toneladas em 2027 (AVINEWSBRASIL, 2017) 
De acordo com Oliveira (2016) é feito uma fiscalização em todo território federal, pelo Serviço de Inspeção Federal (SIF) que atua para o controle e inspeções dos abatedouros e frigoríficos de carne de frango em todo país".

\section{PROCEDIMENTOS METODOLÓGICOS}

Para o desenvolvimento da pesquisa foram consultados artigos acadêmicos e periódicos relacionadas ao assunto, assim como sites específicos sobre o mercado de carnes em geral. A pesquisa tem caráter exploratório e qualitativo.

Segundo Gil (2007), os exemplos mais característicos desse tipo de pesquisa são sobre investigações sobre ideologias ou aquelas que se propõem à análise das diversas posições acerca de um problema.

\section{RESULTADOS E DISCUSSÃO}

Segundo a Embrapa (2020) no ano de 2019 a Brasil alcançou o terceiro lugar no ranking de produção mundial, apontando os estados do Paraná, Santa Catarina, Rio Grande do Sul e São Paulo com o maior rendimento de produção do país de carne de frango em tonelada, conforme ilustrado nas figuras 1 e 2 .

Figura 1: Ranking Mundial em escala de Produção em tonelada.

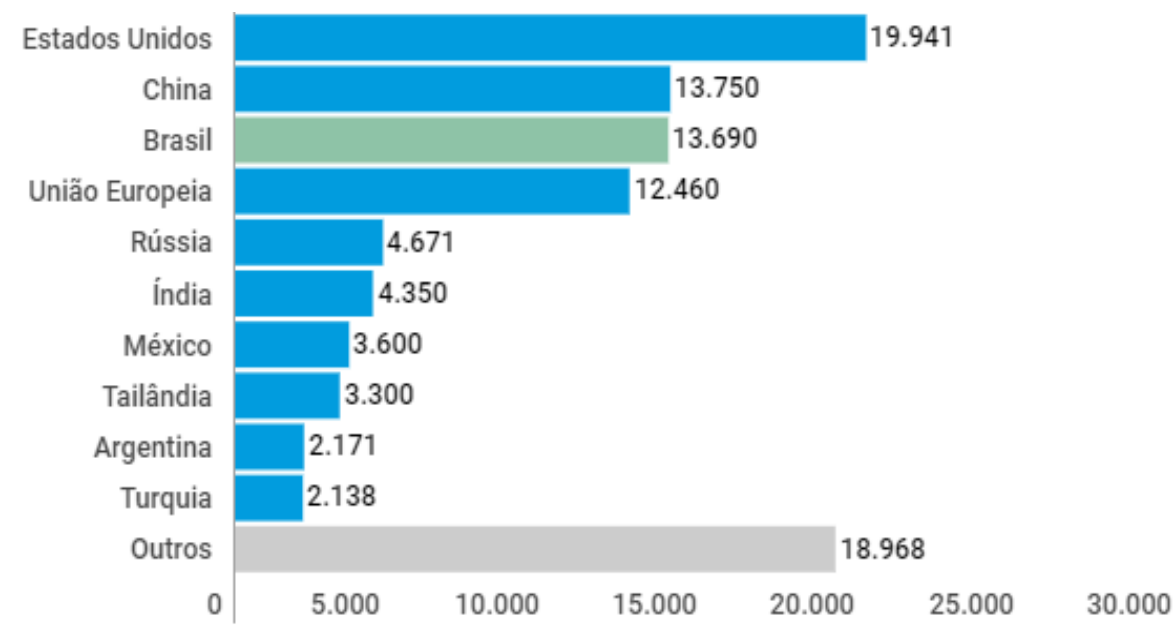

Fonte: USDA | Foreign Agricultural Service (2020)

Figura 2: Ranking Nacional em escala de Produção em tonelada. 


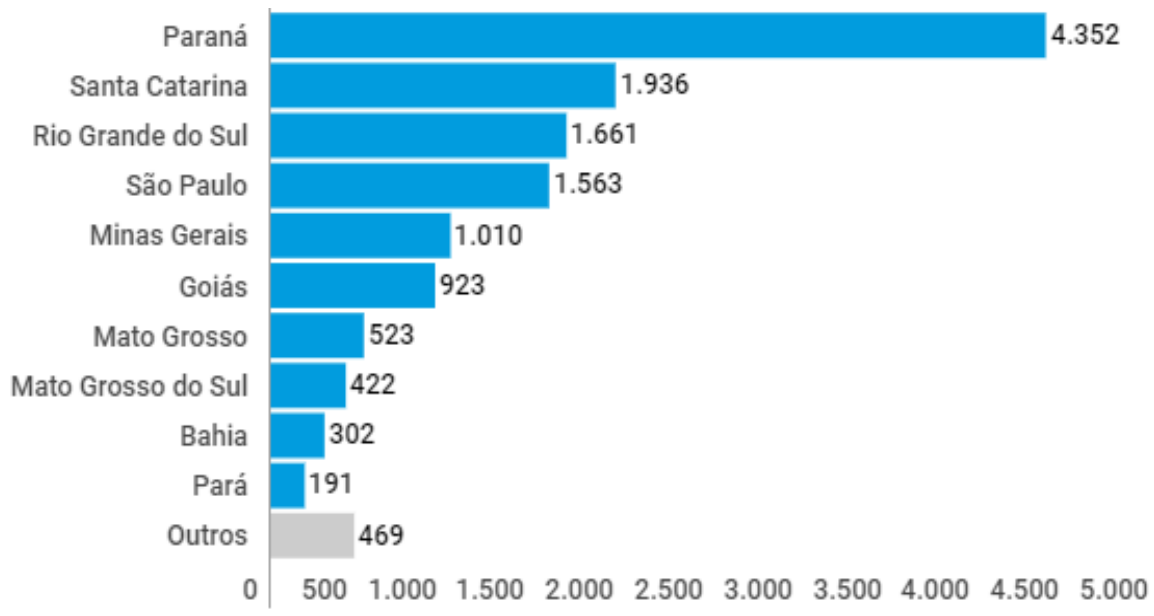

Fonte: Mapa|Agrostat (2020)

As carnes com as maiores taxas de crescimento da produção no período 2020 a 2030 , são as carnes de frango e suína, estimando 2,5\% e 2,4\%, respectivamente (SUÍNO.COM, 2020).

A figura 3 mostra uma comparação da evolução dos custos de produção entre as carnes de frango e suína, de junho de 2019 a junho de 2020.

Figura 3: Custos de produção

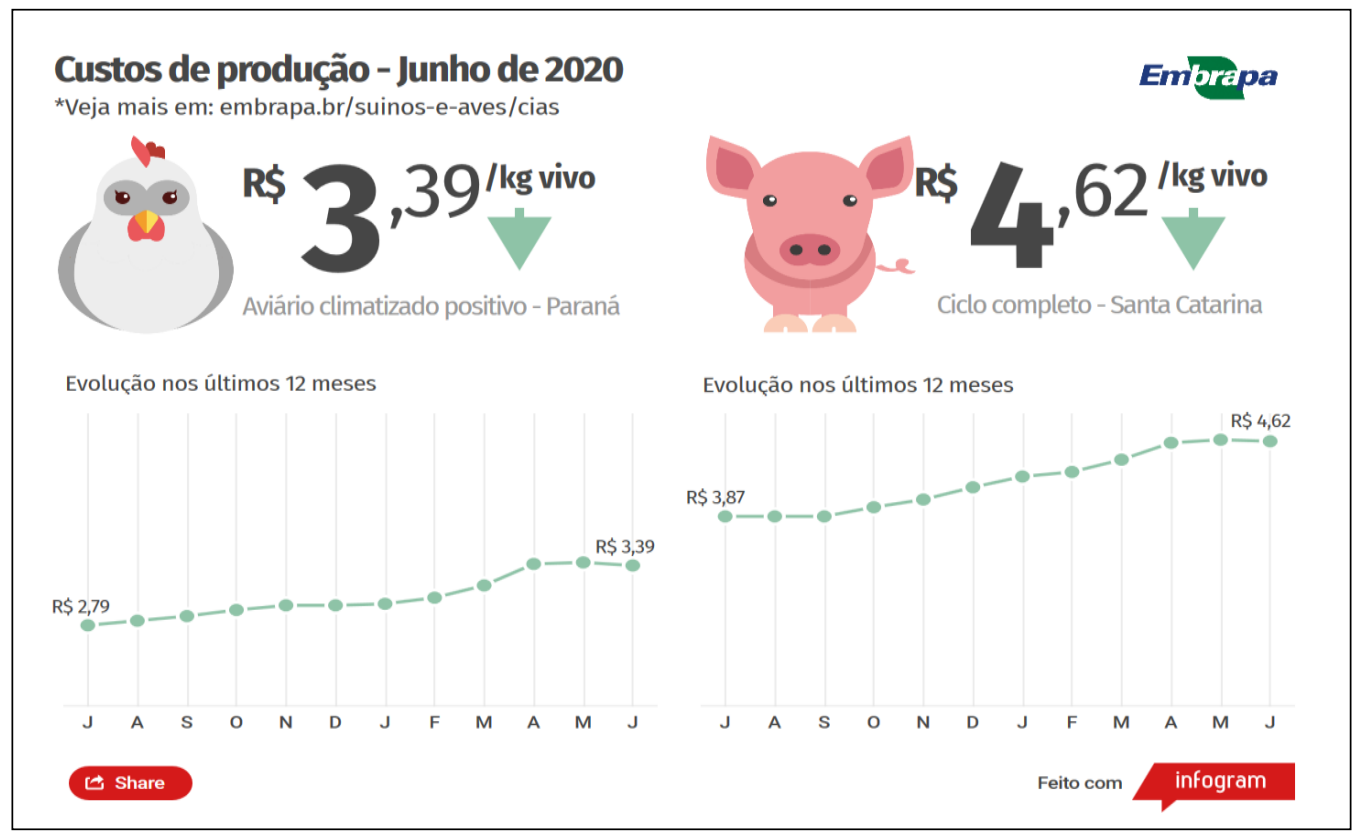

Fonte: EMBRAPA (2020)

Devido a produção do frango caipira estar concentrada a maior parte com os produtores familiares desde o fim da Segunda guerra mundial, nos dias de hoje esse mercado vem se 


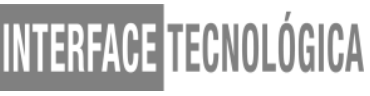

destacando cada vez mais por conta do diferencial da carne e por ser uma das carnes mais primordiais e nobres da mesa do consumidor. Segundo a Gazeta do Povo (2012) as galinhas caipiras cridas ao ar livre não competem com as aves industriais (galinhas brancas e tradicionais de granjas), mas sua participação no mercado está aumentando a cada dia. Ela também diz que os consumidores estão dispostos a pagar um preço maior pela mercadoria, por conta do diferencial e os benefícios que a carne tem.

Com o crescimento de $20 \%$ e contando com 5 milhões de aves produzidas por mês no ano de 2016 (CANAL RURAL, 2016). Avicultura Industrial (2016) diz que a identificação do produto começa com o processo de criação. É feito o abate das aves por voltas dos 70 dias de vida, tendo uma diferença de 25 dias em relação ao abate das aves industriais, se tornando um setor muito mais atrativo ao mercado de frangos alternativos. Com es se tipo de produção, podem ser obtidos mais produtos naturais, agregando muitos benefícios, como produtos sem aditivos químicos que por vez vem se valorizando a cada dia pelos consumidores (SEBRAE, 2014).

\section{CONSIDERAÇÕES FINAIS}

\begin{abstract}
Mesmo com o período difícil que o Brasil e o mundo todo está passando, por conta da pandemia do Covid-19, assim a AVINEWSBRASIL (2020) informa que em esclarecimento do IPC "A carne de frango é uma parte essencial de uma dieta nutritiva para consumidores em todo o mundo e continua segura para consumo na era pandêmica da COVID-19, seja produzida internamente ou importada do exterior". A afirmação consta na nota do International Poultry Council (IPC), divulgada no dia 21/08/2020.
\end{abstract}

A positividade e altas expectativas no meio econômico estão grandes, onde o assunto sobre investimentos futuros estão em pautas nas reuniões. Especialmente falados pelas cooperativas agropecuárias, que nos últimos tempos tem-se revelado um pioneiro no âmbito do agronegócio nacional. (AVICULTURAINDUSTRIAL, 2018)

A análise das tendências do mercado de carne de frango evidencia o grande potencial de crescimento, sendo este produto um dos principais do agronegócio brasileiro na atualidade, responsável por 13,15 milhões de toneladas de produção no ano de 2019 atingindo US\$ 6,358 bilhões nas exportações com um acréscimo de 6,1\% em relação ao ano de 2018 segundo (AGENCIABRASIL, 2019) 


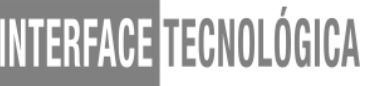

Por sua vez, o frango caipira, por tratar de um mercado emergente, apresenta índices de crescimento consistentes, porém é um mercado ainda caracterizado pela produção informal em sua maioria, com grande potencial de exploração no mercado interno.

Considerando-se estes fatores, aliados ao tempo de criação de 70 dias o frango caipira tem custos de produção ainda altos para os padrões brasileiros, ficando restrito às classes $\mathrm{A} e$ B. Certamente com o aumento na escala de produção os valores de mercado tenderão a diminuir, permitindo o acesso de um público maior

\section{REFERÊNCIAS}

ABBAD E, B.E. O papel do agronegócio brasileiro no seu desenvolvimento econômico. GEPROS. Gestão da Produção, Operações e Sistemas. Julho de 2014. Disponível em: https://revista.feb.unesp.br/index.php/gepros/article/viewFile/1053/594 . Acessado em: $09 / 10 / 2020$

ABPA. 2019. ABPA: ABPA PROJETA FORTE AUMENTO DA EXPORTAÇÃO DE CARNE DE FRANGO E SUÍNA EM 2019. Disponível em: http://abpa-br.org/abpa-projetaforte-aumento-da-exportacao-de-carne-de-frango-e-suina-em-2019/. Acessado em: $09 / 10 / 2020$

ALBUQUERQUE, F. Setor prevê fechar 2019 com aumento da produção de carne de frango. Agência Brasil - São Paulo. Dezembro de 2019. Disponível em: https://agenciabrasil.ebc.com.br/economia/noticia/2019-12/setor-preve-fechar-2019-comaumento-da-producao-de-carne-defrango\#: :text=A\%20produ $\% \mathrm{C} 3 \% \mathrm{~A} 7 \% \mathrm{C} 3 \% \mathrm{~A} 3 \mathrm{o} \% 20 \mathrm{de} \% 20$ carne $\% 20 \mathrm{de}$, milh $\% \mathrm{C} 3 \% \mathrm{~B} 5 \mathrm{es} \% 2$ 0de\%20toneladas\%20de\%202018. Acessado em: 09/10/2020

AVINEWSBRASIL, COVID-19: carne de frango continua segura,diz IPC. Fonte: Assessoria da Imprensa IPC. Agosto de 2020. Disponível em: https://avicultura.info/pt-br/carne-defrango-segura-ipc-covid-19/ Acessado em: 09/10/2020

AVINEWSBRASIL. Brasil: produção de carne de frango é a que mais crescerá em dez anos. Marketing\&Economia. Julho de 2017. Disponível em https://avicultura.info/pt-br/brasilproducao-carne-de-frango-dez-anos/ Acessado em: 09/10/2020

AVISITE. Em 2020 a carne de frango será a mais consumida do mundo. Portal da Avicultura da Internet. Junho DE 2013. Disponível em:

https://www.avisite.com.br/noticias/imprimir.php?codnoticia=14231 Acessado em: $09 / 10 / 2020$

BARBOSA, V.J.F. NASCIMENTO, B.S.P.M. DINIZ, M.F. NASCIMENTO, S.T.H. NETO, A.B.R. Sistema alternativo de criação de galinha caipira. Sistema de Produção 04 . 
Teresina, Julho de 2007. Disponível em:

https://ainfo.cnptia.embrapa.br/digital/bitstream/item/80710/1/sistemaproducao-4.PDF Acessado em: 09/10/2020

CARRIJO, S.A. MADEIRA, A.L. SARTORI, R.J. PEZZATO, C.A. GONÇALVES, C.J. CRUZ, C.V. KUIBIDA, V. K. PINHEIRO, F.D. Alho em pó na alimentação alternativa de frango de corte. Pesquisa agropecuária. brasileira. Julho de 2005. Disponível em: https://www.scielo.br/scielo.php?pid=S0100204X2005000700008\&script=sci_arttext\#: :text=A\%20administra\%C3\%A7\%C3\%A3o\%20 de\%20alho\%20em,de\%20trombose $\% 20 \mathrm{e} \% 20$ anomalias\%20cardiovasculares. Acessado em: $09 / 10 / 2020$

COMUNIDADE. Brasil deve produzir 10,5 milhões de toneladas de carne bovina em 2020, diz USDA. Fevereiro de 2020. Disponível em: https://comunidadeviadutos.com.br/site/noticia/brasil-deve-produzir-10-5-milhoes-detoneladas-de-carne-bovina-em-2020--diz-usda./6479 Acessado em: 09/10/2020

CONAB. Carne de Frango. Análise Mensal. Agosto de 2017, Disponível em: file://C:/Users/Larissa\%20Izac/Downloads/Carne_de_frango_-_Analise_Mensal_-_agosto2017\%20(2).pdf Acessado em: 09/10/2020

CONTINI, E.MARTHA, JUNIOR, G. B. Brazilian agriculture, its productivity and change. Bertebos Conference on "Food security and the futures of farms: 2020 and toward 2050". Falkenberg: Royal Swedish Academy of Agriculture and Forestry, August 29-31, 2010. https://pt.scribd.com/document/108636185/Brazilian-Agriculture-Its-Productivity-andChange Acessado em: 09/10/2020

DA SILVA, A.L.J. Avaliação da Gestão do Uso e Reuso de Água em Abatedores de Aves. Universidade Federal de Pernambuco. Abril de 2007. Disponível em: https://repositorio.ufpe.br/bitstream/123456789/6441/1/arquivo8169_1.pdf Acessado em: $09 / 10 / 2020$

EMBRAPA. Maiores produtores e exportadores. Central de Inteligência de Aves e Suínos. Maio de 2020. Disponível em: https://www.embrapa.br/suinos-eaves/cias/estatisticas/frangos/brasil Acessado em: 09/10/2020

EMBRAPA. Qualidade de carne de Aves. Empresa Brasileira de Pesquisa Agropecuária. 2020. Disponível em: https://www.embrapa.br/qualidade-da-carne/carne-de-aves Acessado em: 09/10/2020

FREITAS, M.G. Propositura de investimento para a criação de frango caipira na perspectiva do pequeno produtor. Secretaria de Educação Profissional e Tecnológica Instituto Federal de Educação, Ciência e Tecnologia Goiano. Fevereiro de 2020. Disponível em: https://repositorio.ifgoiano.edu.br/bitstream/prefix/1013/1/tcc_\%20Guilherme\%20Freitas.pdf Acessado em: 09/10/2020

G1. Globo. O Brasil se consolida com o $2^{\circ}$ maior produtor de carne de frango. GLOBO RURAL. Janeiro de 2016. Disponível em: 
http://g1.globo.com/economia/agronegocios/noticia/2016/01/brasil-se-consolida-como-2maior-produtor-de-carne-de-frango.html Acessado em: 09/10/2020

GAZETA DO POVO. Galinha caipira ganha escala comercial. Agricultura, Julho de 2012. Disponível em: https://www.gazetadopovo.com.br/agronegocio/agricultura/galinha-caipiraganha-escala-comercial- Acessado em: 09/10/2020

GHERARDI, M.R.S. Abate e processamento de carne de frango. Instituto Federal Goiano. 2013. Disponível em:

file://C:/Users/Larissa\%20Izac/Downloads/Aba_Proc_Carn_Frang_WEB_AZ\%20(1).pdf Acessado em: 09/10/2020

GIL, A.C. Métodos e técnicas de pesquisa social. São Paulo: Atlas, 2007.

JUNIOR, S.C.J. ROCHA, T.R.F. COELHO, O.K. Análise bibliométrica sobre galinhae frango caipira/ colonial. Research, Society and Development. Julho de 2020. Disponivel em: file:///C:/Users/Larissa\%20Izac/Downloads/6354-Article-28702-1-10-20200719.pdf Acessado em: 09/10/2020

MARQUES, L.H. Anuário da Avicultura Industrial: 2019 será melhor para a avicultura. Avicultura Industrial. Dezembro de 2018. Disponível em:

https://www.aviculturaindustrial.com.br/imprensa/anuario-da-avicultura-industrial-2019-seramelhor-para-a-avicultura/20181213-144930-u650 Acessado em: 09/10/2020

Ministério da Agricultura, Pecuária e Abastecimento. Plano Agrícola e Pecuário 2011- 2012 / Ministério da Agricultura, Pecuária e Abastecimento. Secretaria de Política Agrícola. Brasília: Mapa/SPA. 2011. Disponível em:

http://faef.revista.inf.br/imagens_arquivos/arquivos_destaque/2OPWO6AlLTgjCrp_2013-624-15-3-44.pdf Acessado em: 09/10/2020

MORAIS, J. FERREIRA, B.P. JACOME, D.T.M.I. MELLO, R. BREDA, C.F. RORATO, N.R.P. Curva de crescimento de diferentes linhagens de frango de corte caipira. Ciência Rural, Santa Maria, Online. Maio de 2015. Disponível em: https://www.scielo.br/pdf/cr/2015nahead/0103-8478-cr-cr20130867.pdf Acessado em: $09 / 10 / 2020$

OLIVEIRA, A.A. ANDRADE, A.M. ARMENDARIS, M.P. BUENO, S.H.P. Principais causas de condenação ao abate de aves em matadouros frigoríficas registrado no serviço brasileiro de inspeção federal entre 2006 to 2011. Medicina Veterinária. Março de 2016. Disponível em: https:/www.scielo.br/pdf/cab/v17n1/1809-6891-cab-17-01-0079.pdf Acessado em: 09/10/2020

OLIVEIRA, J. F. de et al. Aves Caipira. Circuito de tecnologias adaptadas para a agricultura familiar. 2008. Disponível em:

https://www.bibliotecaagptea.org.br/zootecnia/avicultura/livros/SISTEMA\%20ALTERNATI VO\%20DE\%20PRODUCAO\%20DE\%20AVES.pdf Acessado em: 09/10/2020 


\section{WTEERFAEETECWNOLOGGCA}

PACHECO, M.A., SANTOS, C.R.I., HAMZÉ, L.A., MARIANO, G.S.R., SILVA, F.T., ZAPPA, V., A Importância do agronegócio para o Brasil - Revisão Literária. Revista

Científica Eletrônica de Veterinária. Julho de 2012. Disponível em:

http://faef.revista.inf.br/imagens_arquivos/arquivos_destaque/2OPWO6AlLTgjCrp_2013-624-15-3-44.pdf Acessado em: 09/10/2020

SEBRAE MERCADOS. O mercado e a produção de galinha caipira no Brasil. Sebrae Respostas. Abril de 2014. Disponível em: https://respostas.sebrae.com.br/mercado-eproducao-de-galinha-caipira-no-brasil/ Acessado em: 09/10/2020

SOUZA, K. M. R., CARRIJO, A. S., KIEFER, C., FASCINA, V. B., FALCO, A. L., \& MANVAILER, G. V.; GARCÍA, A. M. L. (2009). Farelo da raiz integral da mandioca em dietas de frango caipira. Archivos de Zootecnia. Disponível em:

http://scielo.isciii.es/pdf/azoo/v60n231/art38.pdf Acessado em: 09/10/2020

SOUZA, X.R. Características de carcaça, qualidade de carne e composição lipídica de frangos de corte criados em sistemas de produção caipira e convencional. Tese de Doutorado (Ciência e Tecnologia de Alimentos) - Faculdade de Zootecnia, Universidade Federal de Lavra. 2004. Disponível em: https://teses.usp.br/teses/disponiveis/11/11141/tde-20092006145939/publico/AnaAguiar.pdf Acessado em: 09/10/2020

SUINO.COM. Mapa projeta liderança do frango na produção e consumo a década de 2020/30. Julho de 2020. Disponível em: https://www.suino.com.br/mapa-projeta-liderancado-frango-na-producao-e-consumo-para-a-decada-2020-

30/\#: : text=Entre $\% 20$ as $\% 20$ carnes $\% 2 \mathrm{C} \% 20$ as $\% 20$ que, $2 \% 2 \mathrm{C} 4 \% 25 \% 2 \mathrm{C} \% 20$ respectivamente. \&text $=\mathrm{O} \% 20$ maior $\% 20$ aumento $\% 20 \mathrm{de} \% 20$ produ $\% \mathrm{C} 3 \% \mathrm{~A} 7 \% \mathrm{C} 3 \% \mathrm{~A} 3 \mathrm{o}$,bovina $\% 2 \mathrm{C} \% 2016 \% 2$ C2\%25. Acessado em: 09/10/2020

THE ECONOMIST. The miracle of the cerrado: Brazil has revolutionized its own farms. Can it do the same for others. Aug 26th, 2010.

VENTURINI, K. S.; SARCINELLI, M. F.; SILVA, L. C. Características da carne de frango. Boletim Técnico, Universidade Federal do Espírito Santo. 2007. Disponível em: http://www.agencia.cnptia.embrapa.br/Repositorio/caracteristicas_da_carne_de_ frango_000fy1kfoyu02wx5ok0pvo4k3r15t9pj.pdf. Acessado em: 09/10/2020 